\section{Elements of Science Fiction}

While writing Historical Notes for the past 80 months, I have also been writing science fiction novels and am now facing several new contracts, and three unwritten novels due within the next few months. So I must finally hang up my hat as author of Historical Note.

Fittingly, my last Note presents an overview of exotic hypothetical materials proposed by classic scientific writers, extrapolated from the best scientific knowledge of their day.

From the days of the garish pulp magazines in the 1930s and 1940s, and even before, science fiction has a reasonably good track record of predicting new technologies. Some of these successes are well-known, such as the submarine, airplane, spaceflight, television, air warfare, computers, satellites and satellite communications, cloning, and robots.

Many classic science fiction stories proposed exotic new materials that were put to fascinating uses. Some of these "science fictional" materials have become reality today, such as plexiglass and high-temperature superconductors, not to mention numerous variations of "plasteel," "glasstic," and "transparisteel" substances. But some of the proposed materials are still waiting to be invented.

In 1901 H.G. Wells proposed an antigravity substance called "cavorite" in his novel, The First Men in the Moon (in The Complete Science Fiction Treasury of H.G. Wells, Avenel Books, 1934). The narrator of the story writes, "Here is a substance...no home, no factory, no fortress, no ship can dare to be without-more universally applicable even than a patent medicine! There isn't a solitary aspect, not one of its ten thousand possible uses, that will not make us rich" (p. 401).

But how does it work? The narrator explains that cavorite was "a substance that should be 'opaque...to all forms of radiant energy.' 'Radiant energy,' [the inventor] made me to understand, was anything like light or heat or those Roentgen rays there was so much talk about a year or so ago, or the electric waves of Marconi, or gravitation....

"Now almost all substances are opaque to some form or other of radiant energy. Glass, for example, is transparent to light, but much less so to heat, so that it is useful as a fire screen... Now all known substances are 'transparent' to gravitation. You can use screens of various sorts to cut off the light or heat or electrical influence of the sun...you can screen things by sheets of metal from Marconi's rays, but nothing will cut off the gravitational attraction of the sun or the gravitational attraction of the earth. Yet why there should be nothing is hard to say" (p. 399).

The inventor, explains the narrator, developed a way to manufacture "a complicated alloy of metals and something new-a new element I fancy-called, I believe, helium, which was sent to him from London in sealed stone jars. Doubt has been thrown upon this detail, but I am almost certain it was helium he had sent him in sealed stone jars. It was certainly something very gaseous and thin. If only I had taken notes..." (p. 399). After some playful activities with the antigravity cavorite, the adventurers build a sphere of the material and travel to the moon.

Jules Verne, whose name is often spoken in the same breath as Wells (though Verne actually wrote his most famous novels several decades earlier), was apparently upset with Wells's laissezfaire approach to science. "Where is this 'cavorite?' Show it to me!" he reportedly said in disgust, "It does not exist."

Actually, Wells extrapolated his material from respectable scientific research of the day, particularly from a paper J.H. Poynting published in 1900 in Nature describing a series of experiments underway to discover or develop a material that could screen out gravity.

Another exotic substance waiting to be invented appears in Bob Shaw's 1966 story "Light of Other Days," which describes the material "slow glass," a transparent substance with an effective index of refraction so great that it takes light years to pass through it.

"[E]very photon of ordinary light passed through a spiral tunnel coiled outside the radius of capture of each atom in the glass.... The most important effect, in the eyes of the average individual, was that light took a long time to pass through a sheet of slow glass. A new piece was always jet black because nothing had yet come through, but one could stand the glass beside, say, a woodland lake until the scene emerged, perhaps a year later. If the glass was then removed and installed in a dismal city flat, the flat would-for that year-appear to overlook the woodland lake. During the year...the water would ripple in the sunlight, silent animals would come to drink, birds would cross the sky, night would follow day, season would follow season. Until one day, a year later, the beauty held in the subatomic pipeline would be exhausted and the familiar gray cityscape would reappear" (in Analog 6, Doubleday, 1968).

Shaw proposed an entire industry of people who have slow-glass "farms" of scenic hillsides covered with panes of slow glass, soaking up the scenery for years. Charlatans try to pass off panes of regular glass covered with a thin veneer of slow glass "only a few weeks thick."

Most importantly, a pane of slow glass must be in phase, "A coarse discrepancy could mean that a pane intended to be five years thick might be five and a half, so that light which entered in summer emerged in winter; a fine discrepancy could mean that noon sunshine emerged at midnight. These incompatibilities had their peculiar charm-many night workers, for example, liked having their own private time zones" (pp. 212-214).

Science fiction has come up with many other substances to challenge the imaginations of materials scientists. Writers have proposed any number of impenetrable metal alloys, from "adamantium," the substance used for Captain America's shield, as comics buffs will know, to "neutronium," which is supposedly formed in a supernova collapse.

Monomolecular fibers have been used time and again, in Arthur C. Clarke's The Fountains of Paradise, Daniel Keys Moran's The Long Run and The Last Dancer, and my own Lifeline (coauthored with Doug Beason).

Twenty-five years ago in one of the first episodes of Star Trek, Captain Kirk outbluffs an enemy alien by claiming that the Enterprise is constructed of a material called "corbomite." Corbomite reflects and channels all incident destructive energy back to its source, thereby destroying any attacker. The enemy decides not to risk an attack. Star Trek also gives us "dilithium crystals" for energy storage, and the formula for "transparent aluminum" in exchange for sheets of plexigalss (in Star Trek IV).

These ideas have been around for decades, just waiting to be invented.

Today, it's still science fiction-but it doesn't have to be.

I have enjoyed writing Historical Notes for the past six and a half years. And for now, I am off to another galaxy...

KEVIN J. ANDERSON

Kevin J. Anderson's books include the Star Wars novels: Jedi Search, Dark Apprentice, and Champions of the Force; and a recent novel about Mars, Climbing Olympus. He and Doug Beason have coauthored Lifeline, The Trinity Paradox, and Assemblers of Infinity. 


\section{GROUP THEORY IN CHEMISTRY AND SPECTROSCOPY} A Simple Guide to Advanced Usage

\section{Boris S. Tsukerblat}

Institute of Chemistry, Academy of Sciences of Moldova

A Volume in the THEORETICAL CHEMISTRY Series

Group theory inferences are widely applied to analyze the results of practically all spectroscopic methods used in organic and inorganic chemistry. Accordingly, group theory has become the working tool of chemists who not only synthesize new substances but also investigate their electronic structure and properties. This book is a manual for experimentalists, and all the fundamental concepts are introduced by way of simple examples that solve particular chemical and physical problems. In line with the practical bias of the book, the main results are presented as recipes for step-by-step use in practice. Every chapter contains problems which develop practical skills.

CONTENTS (Chapter Headings): Symmetry Transformations and Groups. Point Groups and Their Classes. Representations of Point Groups. Crystal Field Theory for One-Electron Ions. Many-Electron Ions in Crystal Fields. Semiempirical Crystal Field Theory. Theory of Directed Valence. Molecular Orbital Method. Intensities of Optical Lines. Double Groups, Spin-Orbit Interaction in Crystal Fields. Electron Paramagnetic Resonance. Exchange Interaction in Polynuclear Coordination Compounds. Vibrational Spectra and Electron-Vibrational Inter actions. Appendixes. References. Subject Index.

1994, 430 pp., \$65.00/ISBN: 0-12-702285-6

\section{PHASE DIAGRAMS IN}

\section{ADVANCED CERAMICS}

Edited by

Allen M. Alper

A Volume in the TREATISE ON MATERIALS SCIENCE AND TECHNOLOGY Series

This book reviews some of the recent advances in the understanding of multi-component complex systems composed of oxides, nitrides, and carbides. It provides insight into how phase diagrams can be utilized in the fabrication of whiskers and ceramic-matrix whisker-reinforced ceramics. Phase relations and sintering information is reviewed for transparent polycrystalline oxides. Phase diagrams are discussed to predict alkali oxide corrosion of alumino-silicate references.

CONTENTS: Phase Chemistry in the Development of Transparent Polycrystalline Oxides. The Use of Phase Diagrams to Predict Alkali Oxide Corrosion of Ceramics. Application of Phase Diagrams to the Production of Advanced Composites. Use of Phase Diagrams in the Study of Silicon Nitride Ceramics. The Use of Phase Studies in the Development of Whiskers and Whisker-Reinforced Ceramics. Chapter References. Subject Index.

December 1994, c. 237 pp. \$89.95 (tentative)/ISBN: 0-12-341834-8

Order from your local bookseller

or directly from

AP ACADEMIC PRESS, Inc.

Order Fulfillment Department DM27098 6277 Sea Harbor Drive, Orlando, FL

CALL TOII FREF: 800-321-5068

FAX TOLL FREE: 800-336-7377

E-MAll: ap@acad.com

Prites subject to change without notice. (C) 1995 by Academic Press, Inc. All Rights Reserved.

NS/E/SW/PECS- 09025
Stay Current with

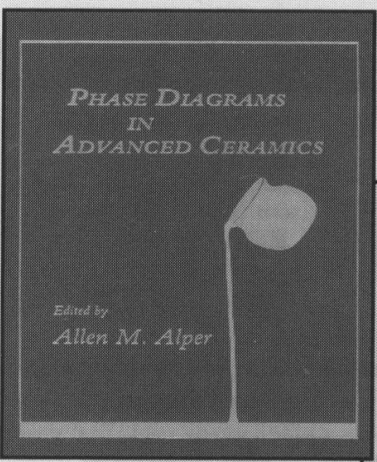

NEW

MATERIAL

Nucleophilic

Aromatic

Substitution

of Hydrogen

MULTIDIMENSIONAL SOLID-STATE NMR AND POLYMERS
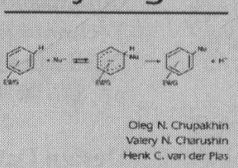

(Ai)

Klaus Schmidt-Rohr and Hans Wolfgang Spiess

NMR spectroscopy is the most valuable and versatile tool in chemistry and this is the first book to address multidimensional solid-state NMR. Multidimensional techniques enable researchers to obtain detailed information about the structure, dynamics, orientation, and phase separation of solids, which provides the basis of a better understanding of materials properties on the molecular level. Dramatic progress - much of it pioneered by the authors-has been achieved in this area, especially in synthetic polymers. Solid-state NMR now favorably competes with well-established techniques, such as light, $\mathrm{x}$-ray, or neutron scattering, electron microscopy, and dielectric and mechanical relaxation.

November 1994, 496 pp., \$99.95/SBN: 0-12-626630-1

\section{NUCLEOPHILIC AROMATIC SUBSTITUTION OF HYDROGEN}

Oleg N. Chupakhin,

Valery N. Charushin, and

Henk C. van der Plas

This book is a comprehensive and coheren survey of the theoretical and practical aspects of the nucleophilic displacement of hydrogen. The text describes the systematic analysis of a vast range of nucleophilic substitutions of aromatic hydrogen in $\mathrm{h}\left[\right.$ or $\left.^{1}\right]$-deficient aromatics such as nitroarenes, arene-metal complexes, pyridines and their aza and benzo analogs, azine N-oxides, $\mathrm{N}$-alkyl, N-acyl, N-alkoxy and $\mathrm{N}$-fluoroazinium salts, and pyrilium and thiapyrilium cations. Numerous original and carefully crafted experimental procedures are provided at the end of each chapter, making the book an invaluable source of practical information for organic chemists working in organic synthesis, heterocyclic chemistry, and pharmaceutical chemistry in industrial and university laboratories.

November 1994, 367 pp., \$95.00/ISBN: 0-12-174640-2

\section{COLLOIDAL POLYMER PARTICLES}

\section{J.W. Goodwin and R. Buscall}

The wide interest in the field of polymer colloids is reflected in this book with chapters covering the preparation and properties of conducting particles, as well as composite particles and swellable particles. Many other materials such as proteins, polymers, polyelectoctrolytes, and surfactants interact strongly with the surface of polymer latex particles and new work on these aspects is covered, along with recent developments in the use of latices.

March 1995, c. 350 pp. $\$ 90.00$ (tentative)/ISBN: 0-12-290045-6

\section{SUPERCONDUCTIVITY}

Charles P. Poole, Jr.

Horacio A. Farach, and

Richard J. Creswick

Superconductivity is an encyclopedic treatment of all aspects of the subject, from classic materials to fullerenes. Emphasis is on balanced coverage, with a comprehensive reference list and significant graphics from all areas of the published literature. Widely used theoretical approaches are explained in detail. Topics of special interest include high temperature superconductors, spectroscopy, critical states transport properties, and tunneling.

\section{Special Features}

- Provides a comprehensive discussion of fullerene superconductivity

- Emphasizes high-temperature superconductivity

- Includes numerous tables with extensive up-todate data on various superconductors

April 1995, c. 496 pp., \$149.00 (tentative)/ISBN: 0-12-561455-1 